\title{
Research and Discussion on the Management System of Teaching Quality in Local Universities
}

\author{
Feng Gao ${ }^{1, a^{*}}$, Qinghong $Q u^{2, b}$ \\ 1Physics College, Baicheng Normal University, Baicheng,137000,China \\ 2 Media College, Baicheng Normal University, Baicheng,137000,China \\ aemail:gaof317@163.com, bemail: quqinghong@163.com, *corresponding author
}

Key words: Local University; Teaching Quality; Management System

\begin{abstract}
The teaching quality management is an important guarantee to improve the teaching quality of local colleges and universities. It is the focus of the current study how to improve the level of the teaching quality management as well as the key to the teaching reform of local colleges and universities. The teaching quality management is necessary not only for ensuring unity of teaching scientific ant artistry, rectifying the teaching style and study style, enhancing teacher's ethics and quality, but also for improving teaching level and promoting the status of the university. The problems of teaching quality and the strategies to prefect the management system is re proposed according to related literature material in this article.
\end{abstract}

\section{Introduction}

"Education is the cornerstone of national renewal and social progress; work hard to run education for the satisfaction of the people ", which was proposed in the Eighteenth National Congress of the Communist Party of China in 2012. It is the core task for the higher education in China to improve the quality of education of local universities. The scale of local universities in China has been broadened rapidly and the higher education in China historically has entered the stage of popularization away from the stage of elite education since 1999, when the colleges and universities began to expand. Many scholars proposed that nowadays the opinions of teaching quality should be set up and developed to be suitable for China's national conditions[1].

Teaching quality is the lifeline of higher education. Quality monitoring is one of the most important segments of teaching management to enhance the status of local universities. Perfect quality monitoring systems are necessary for higher education to improve the quality of personnel training. Cultivating high-quality talents for the development of regional economic society is one of the most important responsibilities of local universities, which can be achieved by improving teaching quality and modifying the monitoring systems.

\section{The necessities for local universities to establish the management systems of teaching quality}

With the expansion of higher education, there have been many changes in student quality, student-teacher ratios, curriculum setups, specialized subjects, teaching modes and methods. First, the student-teacher ratios have become much higher than those stipulated by the Ministry of Education of the Republic of China, and the faculties are short of in local universities, which not only has increased the amounts of teachers' tasks and prevents the teaching quality from improving, but also has positive impacts on the teaching practices and researches of university teachers. Second, the lack of effective rules and regulations to supervise the educational quality has become a problem for local universities to monitor the teaching quality and it is difficult for the universities to deal well by original monitoring systems with the problems of the increasing in the number of students and the scale of the universities. Third, teachers pay more attention to articles and scientific research but less attention to teaching practices, which has become a bottleneck to hold back the improvement of teaching quality[2]. It is necessary for local universities to develop appropriate teaching quality management systems, which are composed of the file systems of teaching quality, the principal parts of management systems and the 
systems of management methods(see Figure 1).

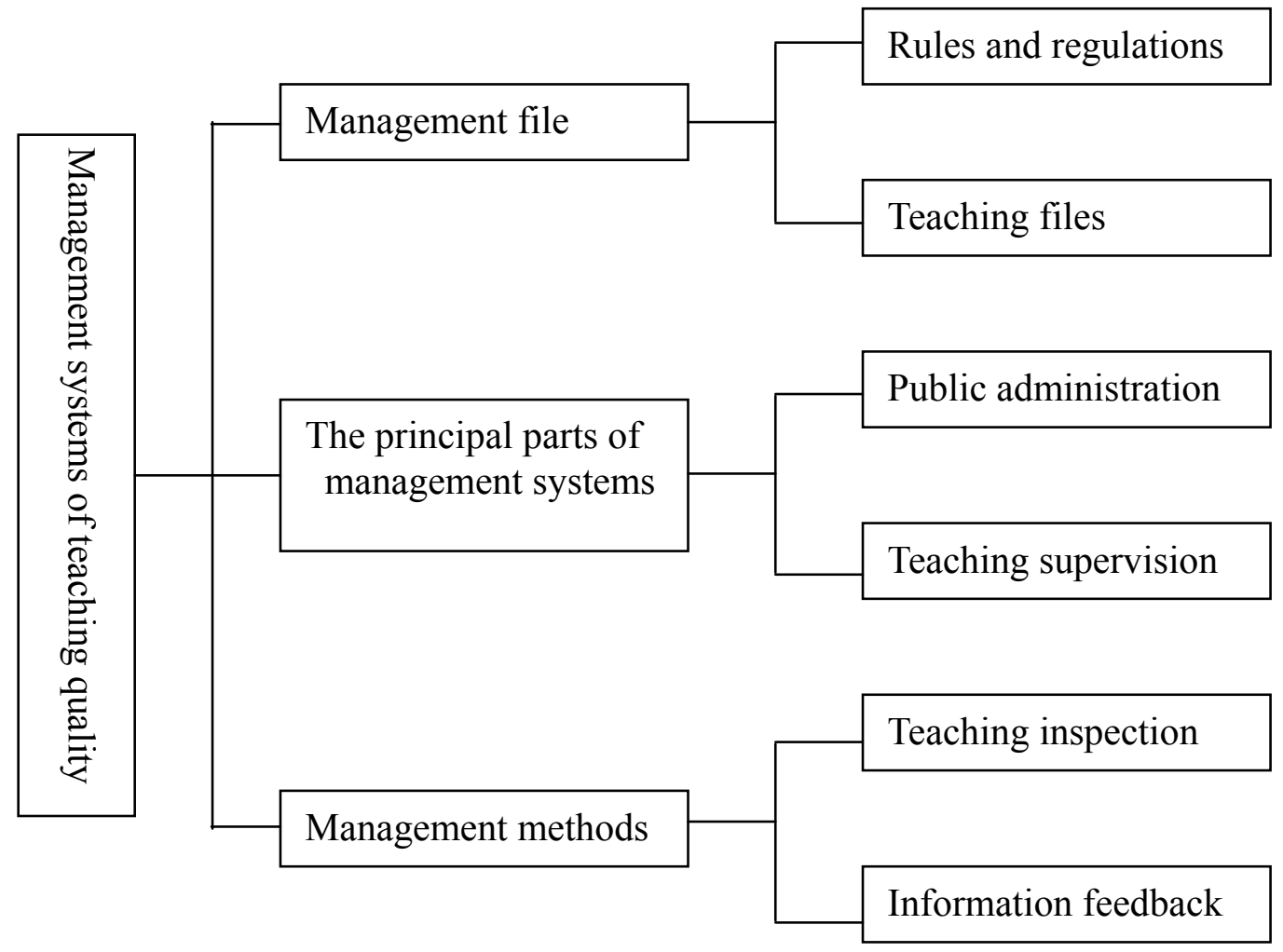

Fig.1. Management systems of teaching quality

\section{The current existing problems of management systems of teaching quality in local universities}

The administration of teaching quality has not been perfected in local universities. Perfect teaching quality management systems play an important role in the improvement of quality assurance system. There is no perfect teaching quality management system in local universities, with which it is not possible for these universities to proceed of quality assurance system. Detailed rules and regulations should be drafted based on the standard around China to construct the teaching quality management system in local universities.

There is a lack of awareness in improving teaching quality among some teachers and administrators. For some teachers, they don't take teaching quality serious, fail to promote the teaching quality in class and just finish their teaching tasks. The inefficient supervision in teaching quality is caused by the lack of ideas of quality assurance in practices and the indistinct division of the responsibilities among some administrators[3].

There is a lack in corresponding mechanisms of constraint, reward and punishment to guarantee the teaching quality. The reward and punishment to high or low teaching quality are not reflected well in local universities, although attention has been paid much, which influence the promotion of the level of teaching quality management in local universities.

\section{Strategies of promoting the level of management system of teaching quality in local universities}

Strategies of promoting the operating mechanisms. Effective rules and regulations to improve the teaching quality management should be drafted, with which it can be make sure to evaluate the teaching quality by promoting a range of teaching methods and processes that relate to quality. There are three sections, including enhancing the level of management standards, improving the rules and regulations and carrying out the management regularly[4]. Enhancing the level of management standards means 
that all the positive factors of teaching, learning and managing should be aroused, the management goals should be defined, the management level and quality should be improved; improving the rules and regulations means that perfect management rules and regulations should be created, which include the rules and regulations to inspect the teaching files and all teaching processes; carrying out the management regularly means that the teaching circumstances should be arranged, reported and studied in time, which is helpful to improve the level of teaching quality management according to the inspections at different stages in a semester by means visiting classes, holding forums, check parts of students' homework as well as analyzing the test paper and marks.

Strategies of enhancing the procedures of supervision. Supervising institutions of teaching quality should be created under the management of college and university in local universities, and corresponding supervised teacher groups of the college level and university level should be set up, too. Members from supervising committees of universities and supervised teacher groups of colleges are selected among the skilled teachers with high academic level, strong sense of responsibilities, rich teaching experiences and familiar with teaching regularities, who visit classes frequently to inspect the teaching quality and supervise the teaching procedures to improve the teaching quality and teaching level of the classes by means of visiting and listening classes, surveys, forums and interviews. The leaders and management departments adjust related policies to improve the teaching and management quality with the comments and suggestions on talents cultivation and education reform proposed by the supervisors.

Trategies of feedback. Commenting system should be set up to evaluate teaching quality. Students, who are the carriers of teaching quality, should have a voice on teaching quality in class. Information and suggestions on teaching environment, teachers' behaviors and teaching procedures can be reflected on time by means of feedback boxes and students' forums, which is helpful to promote teaching quality.

Strategies of reinforcing monitoring class teaching quality[5]. Teaching quality monitoring systems should be omnidirectional and multilevel, which include the preparations for teaching and monitoring regulations, such as trial lectures by young teachers, the rules of preparing for lessons together among members of the same teaching and research section as well as the regulations of inspecting the teaching plans. The omnidirectional monitoring systems include the systems of evaluating the teaching procedures by the students, the systems of grading by teachers, the system of visiting classes by peers, managers and supervisors. Problems in teaching practice can be solved effectively by teaching inspection and feedback of teaching information.

\section{Conclusions}

The higher education in China has already entered the stage of popularization away from the stage of elite education and it will be a stern test for the quality of teaching and talent training of undergraduate colleges. The monitoring systems and evaluating systems play key roles in the teaching management systems in universities, which include the supervising management, teaching counseling and evaluating management. The supervising and evaluating systems are the guarantees of teaching quality in Chinese universities, which have immeasurable effects on the operation of universities. Local universities in west Jilin undertake the tasks of educating all kinds of talents with high qualities for the development of economy and society of the local areas. It is very important for the local universities to promote the teaching quality and the levels of management, which is the requirement of integrated development of local universities. It is the high time that attention should be paid to the research on supervising system and evaluating systems of teaching quality in local universities.

\section{References}

[1] Lilai He. The research on the theoretical mode and practical strategies of undergraduate teaching quality control[D]. Southwest University, 2005.

[2] Sifei Xia, Donghong Liu, Lin Yu, etc. Enhance building of teaching quality management system of colleges and universities[J]. Heilongjiang Researches on Higher Education, 2004, 3: 82-84. 
[3] Yuanyuan Wang, Liping Wang. Research and construction of practical teaching quality management system in colleges and universities[J]. Experimental Technology and Management, 2012, 29(7): 14-16.

[4] Allan Ashworth and Roger C Harvey. Assessing quality further and higher education[M]. 1994, London .

[5]Jingbo Ren. Study on monitoring system of teaching quality in higher colleges and universities--take a college in Xuzhou as an example[D]. Nanjing University of Science and Technology, 2012. 